\title{
Combining a Candidate Vaccine for Opioid Use Disorders with Extended-Release Naltrexone Increases Protection against Oxycodone-Induced Behavioral Effects and Toxicity ${ }^{\mathbb{S}}$
}

\author{
Michael D. Raleigh, Claudia Accetturo, and (1) Marco Pravetoni \\ Departments of Pharmacology (M.D.R., M.P.) and Medicine (M.P.), Center for Immunology (M.P.), Medical School, University of \\ Minnesota, Minneapolis, Minnesota; Universita' degli Studi di Milano, Socrates Program, Milano, Italy (C.A.); and Hennepin \\ Healthcare Research Institute, Minneapolis, Minnesota (M.P.)
}

Received March 18, 2020; accepted June 18, 2020

\begin{abstract}
Opioid use disorders (OUDs) and opioid-related fatal overdoses are a significant public health concern in the United States and worldwide. To offer more effective medical interventions to treat or prevent OUD, antiopioid vaccines are in development that reduce the distribution of the targeted opioids to brain and subsequently reduce the associated behavioral and toxic effects. It is of critical importance that antiopioid vaccines do not interfere with medications that treat OUD. Hence, this study tested the preclinical proof of concept of combining a candidate oxycodone vaccine [oxycodone-keyhole limpet hemocyanin $(\mathrm{OXY}-\mathrm{KLH})]$ with an FDA-approved extended-release naltrexone (XR-NTX) depot formulation in rats. The effects of XR-NTX on oxycodone-induced motor activity and antinociception were first assessed in nonvaccinated naïve rats to establish a baseline for subsequent studies. Next, OXY-KLH and XR-NTX were coadministered to determine whether the combination would affect the efficacy of each individual treatment, and it was found that the combination of OXY-KLH and XR-NTX offered greater efficacy in reducing oxycodone-induced motor activity, thigmotaxis, antinociception, and respiratory depression over a range of repeated or escalating oxycodone doses in rats. These data
\end{abstract}

support the feasibility of combining antibody-based therapies with opioid receptor antagonists to provide greater or prolonged protection against opioid-related toxicity or overdose. Combining antiopioid vaccines with XR-NTX may provide prophylactic measures to subjects at risk of relapse and accidental or deliberate exposure. Combination therapy may extend to other biologics (e.g., monoclonal antibodies) and medications against substance use disorders.

\section{SIGNIFICANCE STATEMENT}

Opioid use disorders (OUDs) remain a major problem worldwide, and new therapies are needed. This study reports on the combination of an oxycodone vaccine [oxycodone-keyhole limpet hemocyanin (OXY-KLH)] with a currently approved OUD therapy, extended-release naltrexone (XR-NTX). Results demonstrated that XR-NTX did not interfere with OXY-KLH efficacy, and combination of low doses of XR-NTX with vaccine was more effective than each individual treatment alone to reduce behavioral and toxic effects of oxycodone, suggesting that combining OXY-KLH with XR-NTX may improve OUD outcomes.

\section{Introduction}

Opioid use disorders (OUDs) are a worldwide public health concern, and the World Health Organization estimated that there are 27 million people that suffer from an OUD [WHO, 2018]. In the United States, 2.6 million people are diagnosed with an OUD and at least 50,000 opioid-related fatal overdoses are reported annually (Jones et al., 2018). Clinical and epidemiologic data highlight that current treatment strategies for OUD are still insufficient to curb the occurrence of opioid-related fatal overdoses (Volkow and Collins, 2017).

This work was supported by National Institute of Health National Institute on Drug Abuse [Grant U01 DA038876] (to M.P.) and the Hennepin Healthcare Research Institute Translational Research Program.

https://doi.org/10.1124/jpet.120.000014.

S This article has supplemental material available at jpet.aspetjournals.org.
Approved medications for OUD largely consist of small molecule-targeting opioid receptors. Methadone, an opioid agonist, and buprenorphine, a partial opioid agonist, are effective treatments for OUD, but regulations, abuse liability, and diversion complicate their clinical use (Dodrill et al., 2011; Johanson et al., 2012). Naltrexone, an opioid antagonist used to treat OUD, may be less appealing because it lacks agonist replacement effects and requires an abstinence period before treatment can begin. If patients stop taking naltrexone and resume opioid use, there is also an increased risk of overdose due to loss of opioid tolerance (Miotto et al., 1997). The approval of extended-release naltrexone (XR-NTX) formulations reduced overall mortality compared with oral naltrexone therapy (Kelty and Hulse, 2012). An XR-NTX intramuscular depot formulation (Vivitrol; Alkermes, Waltham, MA) improved antagonist therapy compliance and retention in treatment (Krupitsky et al., 2011, 2013; Coviello et al., 2012;

ABBREVIATIONS: AUC, area under the curve; BBB, blood brain barrier; FDA, Food and Drug Administration; KLH, keyhole limpet hemocyanin; OUD, opioid use disorder; OVA, ovalbumin; OXY, oxycodone; $\mathrm{SaO}_{2}$, arterial oxygen saturation; XR-NTX, extended-release naltrexone. 
DeFulio et al., 2012). This extended-release formulation consisting of NTX embedded in microspheres provides stable plasma NTX concentrations in both animal and human subjects for up to 28 days (Bartus et al., 2003; Dean et al., 2008; Bigelow et al., 2012). XR-NTX decreased hydromorphone effects in human subjects (Bigelow et al., 2012) and blocked fentanyl and hydrocodone effects in rats (Dean et al., 2008). Although XR-NTX improved clinical efficacy of NTX (Krupitsky et al., 2011; Coviello et al., 2012; DeFulio et al., 2012; Kelty and Hulse, 2012), its use and compliance may still be limited by the need for monthly injections and increased likelihood of overdose during relapse or discontinuation of therapy (Kjome and Moeller, 2011). This suggests the need to develop new alternative treatments for OUD and to test their efficacy in combination with current FDA-approved medications.

Vaccines may provide a safe, long-lasting complementary option to treat OUD. Active immunization with opioid-based conjugate vaccines elicits antibodies that selectively bind the target opioid in serum and extracellular fluids and effectively reduce opioid distribution to brain, ultimately blunting opioid-induced behavior and toxicity (Bonese et al., 1974; Anton and Leff, 2006; Stowe et al., 2011; Pravetoni et al., $2012 b$ ). Conjugation of an oxycodone (OXY)-based hapten to native or good manufacturing practice-grade subunit keyhole limpet hemocyanin (KLH) carrier protein generated a vaccine (OXY-KLH) that reduced the distribution of oxycodone and hydrocodone to brain and their subsequent behavioral effects in mice and rats, including acquisition of oxycodone self-administration and oxycodone-induced gene expression in the midbrain (Pravetoni et al., 2013, 2014a,b; Raleigh et al., 2017; Robinson et al., 2019). Similarly, an analogous oxycodone vaccine reduced maintenance of oxycodone intravenous self-administration (Nguyen et al., 2018). Although antidrug vaccines have been highly effective in rodents and primates, clinical trials for nicotine and cocaine vaccines showed proof of efficacy in a subset of high responders (Cornuz et al., 2008; Martell et al., 2009; Hatsukami et al., 2011). To increase efficacy against OUD, combining vaccination and XR-NTX could circumvent the shortcomings of both antibody-and small molecule-based interventions.

The goal of this study was to test whether opioid receptor antagonist therapy could be combined with vaccines against opioids to provide better protection against OUD and possibly overdose. To this end, OXY-KLH and XR-NTX were administered alone or in combination to evaluate their effect on oxycodone-induced antinociception, motor activity, respiratory depression, and bradycardia. Results demonstrated that XR-NTX did not impair oxycodone-specific antibody responses to OXY-KLH and did not interfere with the effects of vaccination on preventing oxycodone-induced motor activity. The combination therapy offered better protection than either treatment alone against opioidinduced locomotor activity, respiratory depression, and bradycardia after repeated exposure to high doses of oxycodone. Although it is acknowledged that combining vaccines with antagonists may limit analgesic options for patients, these data suggest that combination of an antiopioid vaccine with XR-NTX may enhance efficacy of either treatment and may provide extra protection during noncompliance or in treatment-resistant patients.

\section{Materials and Methods}

\section{Animals}

Male Holtzman rats (300-324 g at arrival) were purchased from Envigo (Indianapolis, IN) housed in pairs on a 12/12 hour light/dark schedule and food restricted to $18 \mathrm{~g} /$ day of standard rat chow. Housing and feeding conditions replicated previous preclinical studies of the OXY-KLH vaccine (Pravetoni et al., 2012a, 2013). This study was performed in accordance with the Guide for the Care and Use of Laboratory Animals of the National Institutes of Health. Animal protocols were approved by the Hennepin Healthcare Research Institute Animal Care and Use Committee.

\section{Drugs}

Oxycodone was obtained through Sigma (St. Louis, MO). Oxycodone doses and concentrations were expressed as the weight of the base. Extended-release naltrexone (Vivitrol; Alkermes) was obtained through the Hennepin County Medical Center pharmacy, and its dose was expressed as the weight of the microsphere as provided by the manufacturer.

\section{Vaccine}

An oxycodone-based hapten containing a tetraglycine linker at the C6 position (OXY) was first synthesized and then conjugated to chicken ovalbumin (OVA) or the KLH carrier proteins (Pravetoni et al., 2012a). Rats were immunized with either a decamer native $\mathrm{KLH}$ or a good manufacturing practice-grade subunit KLH (dimer KLH, Stellar Biotechnologies). OXY-KLH was mixed with Freund's adjuvant and administered intraperitoneally as described (Pravetoni et al., 2012a,b). In the final experiment, OXY-KLH was instead adsorbed onto Alhydrogel "85" $2 \%$ aluminum hydroxide (Sergeant Chem, Clifton, NJ) and administered intramuscularly as described (Raleigh et al., 2017, 2018) to determine whether XR-NTX affected immunogenicity of a clinically relevant OXY-KLH formulation. To measure oxycodone-specific serum IgG antibodies postimmunization, ELISA 96-well plates were coated with OXY-OVA or unconjugated OVA control in carbonate buffer and blocked with $1 \%$ gelatin. Primary antibodies were incubated with goat anti-rat IgG antibodies to measure oxycodone-specific serum IgG antibody titers, as described previously (Pravetoni et al., 2012a).

\section{Opioid Level Analysis}

Oxycodone concentrations were measured by gas chromatography/ mass spectrometry as previously described (Raleigh et al., 2017, 2018) and represented as total drug levels. Briefly, trunk blood was centrifuged at $3100 \mathrm{~g}$ for 3 minutes at $4^{\circ} \mathrm{C}$, and serum was collected. Brains were rinsed with distilled water and patted dry. Serum and brains were stored at $-20^{\circ} \mathrm{C}$ until analysis.

\section{Opioid-Induced Motor Activity and Thigmotaxis}

Motor activity studies were conducted during the light cycle. Rats were first given 1 hour to habituate after transport to the behavioral testing room and then injected with saline or oxycodone, according to the experimental design, and placed in an open field (ENV-510S; Med Associates, St. Albans, VT). The entire apparatus was enclosed in a sound-attenuating cubicle. Locomotor activity was monitored via infrared beam breaks and recorded by Activity Monitor 5.0 software (Med Associates). The thigmotaxis index was calculated as the ratio of the distance traveled in the external area to the one traveled in the center, which could be set in the software as a virtual divide (Pravetoni and Wickman, 2008).

\section{Opioid-Induced Respiratory Depression and Bradycardia}

After 1 hour of habituation to the behavioral room, baseline $\%$ arterial oxygen saturation $\left(\mathrm{SaO}_{2}\right)$ and heart rate were assessed 
using a MouseOx (STARR Life Sciences Corp., Oakmont, PA) monitor collar placed around the neck of awake, freely moving rats $(n=8$ each group). Rats further received oxycodone every 17 minutes subcutaneously so that their cumulative oxycodone doses at successive intervals were $2.25,4.5$, and $9.0 \mathrm{mg} / \mathrm{kg}$. Fifteen minutes after each oxycodone injection, 10 -second average $\% \mathrm{SaO}_{2}$ and heart rate were again measured, which took 2 minutes for each animal, resulting in the 17-minute oxycodone-dosing interval. When the last dose was administrated, data were recorded twice 15 minutes apart.

\section{Experiments}

Experiment 1: Effect of Oxycodone on Motor Activity and Thigmotaxis Index in Nonimmunized Rats. Effect of oxycodone $(0,0.25,0.5,0.75$, and $1.0 \mathrm{mg} / \mathrm{kg}$, s.c. $)$ on motor activity was established in nonvaccinated naïve rats ( $n=7$ per dose) to determine oxycodone doses to be used in subsequent studies. Rats were first given saline and habituated to the testing environment and activity chambers on three consecutive daily sessions (test days 1, 2, and 3). Oxycodoneinduced motor activity was then assessed on alternate sessions (test days $4,7,9$, and 11). All testing sessions started immediately after injection, and activity was recorded for 90 minutes. See Fig. 1 for an overview of all experiments.

Experiment 2: Effect of XR-NTX on Oxycodone-Induced Motor Activity, Thigmotaxis Index, Antinociception, and Oxycodone Distribution in Nonvaccinated Naïve Rats. The effect of XR-NTX (Alkermes) on oxycodone-induced motor activity, thigmotaxis index, and oxycodone antinociception was evaluated in nonvaccinated naïve rats. Rats ( $n=8-16$ per group) received either saline or a range of XR-NTX doses $(0,1,2.5,5,25$, and $50 \mathrm{mg} / \mathrm{kg}$, i.m.) on days 0 and 36 to ensure consistent naltrexone serum concentrations throughout the entire study, because it has been shown that XR-NTX's behavioral effects and serum naltrexone are no longer detectable by day 36 (Bartus et al., 2003). This formulation has been previously administered to rats at a dose of $50 \mathrm{mg} / \mathrm{kg}$ i.m., which has been shown to elicit serum naltrexone concentrations of $4-15 \mathrm{ng} / \mathrm{ml}$ for 28 days in rats shortly after administration (Bartus et al., 2003; Dean et al., 2008), which are similar to the therapeutic range observed in humans treated with the same formulation (Bigelow et al., 2012). Rats received saline on days 7,8 , and 9 . Rats received $0.5 \mathrm{mg} / \mathrm{kg}$ oxycodone s.c. on days $10,13,15,17$, and 20 . The oxycodone dose was chosen because it elicited a substantial increase in motor activity in a pilot study (Supplemental Fig. 1). The thigmotaxis index was calculated for each dose of XR-NTX. Two rats had very high thigmotaxis indices (46.5 and 168.5 ) in the $5 \mathrm{mg} / \mathrm{kg}$ group that were unexplained (Supplemental Fig. 2 ). These were determined to be outliers, as detected using ROUT $(\mathrm{Q}=$ $0.1 \%)$, and removed from analysis. On day 43 , the effect of XR-NTX ( 0 , $1,2.5,5,25$, and $50 \mathrm{mg} / \mathrm{kg}$, i.m.) was tested on oxycodone antinociception using a hot-plate set at $54^{\circ} \mathrm{C}$ as previously described (Pravetoni et al., 2013). Nociception was measured at 30 minutes after a dose of $2.25 \mathrm{mg} / \mathrm{kg}$ oxycodone s.c., which was previously shown to elicit a near-maximal antinociceptive response in this test (Pravetoni et al., 2012a, 2013). After reaching the nociceptive behavioral endpoint or the 60 -second cut-off, serum and brain were collected for measurement of oxycodone as described previously (Pravetoni et al., 2013). Percent maximum possible effect was measured as posttest latency to respond minus baseline latency to respond divided by 60 seconds (maximum cut-off) minus baseline latency to respond times 100 .

In an independent experiment, the effect of XR-NTX on the time course distribution and area under the curve (AUC) of serum oxycodone was measured in a separate cohort of nonvaccinated naïve rats injected intramuscularly with either $50 \mathrm{mg} / \mathrm{kg}$ XR-NTX or saline $(n=$ 10 or 11 , respectively) on day 0 . On day 2 , rats were anesthetized with ketamine/dexmedtomidine and implanted with a right jugular vein catheter, which was flushed daily with $200 \mu \mathrm{l}$ of heparinized saline and locked with $25 \%$ glycerol to maintain patency. On day 9 , rats were fasted for 12 hours and dosed with $2.25 \mathrm{mg} / \mathrm{kg}$ s.c. oxycodone, and serum samples were collected at $15,30,60$, and 180 minutes.
Catheters were flushed with $200 \mu \mathrm{l}$ heparinized saline between samples and locked with $50 \mu \mathrm{l}$ of $25 \%$ glycerol after the 60 -minute time point. Estimates for pharmacokinetic parameters, including halflife, maximum concentration $\left(c_{\max }\right)$, time to reach $c_{\max }\left(t_{\max }\right)$, AUC, mean residence time, volume of distribution $(\mathrm{Vd} / \mathrm{F}$, volume over the fraction absorbed), and clearance $(\mathrm{Cl} / \mathrm{F}$, clearance over the fraction absorbed), were obtained from serum concentrations using noncompartmental methods (Pravetoni et al., 2012a, 2013). Some rats were removed from analyses because fewer data points were collected, leading to final group sizes of $n=9$ for XR-NTX and $n=8$ for saline.

Experiment 3: Effect of High Doses of XR-NTX on Oxycodone-Induced Motor Activity in Rats Immunized with OXY-KLH. The effect of mid and high doses of XR-NTX (5 or $50 \mathrm{mg} / \mathrm{kg}$ ) on OXY-KLH vaccine behavioral efficacy was tested in rats to assess whether combining antagonist with vaccination would show increased efficacy compared with each individual treatment. Groups ( $n=8$ /group) were as follows: 1$) \mathrm{KLH}+$ saline, 2$) \mathrm{KLH}+\mathrm{XR}-\mathrm{NTX}, 3$ ) OXY-KLH + saline, and 4) OXY-KLH + XR-NTX. Rats received either saline or $50 \mathrm{mg} / \mathrm{kg}$ XR-NTX i.m. at 0 and 27 days. Concurrently, rats were immunized with either $100 \mu \mathrm{g}$ of the OXY-KLH vaccine or the unconjugated KLH administered on days 0, 21, and 42 in Freund's adjuvant as previously described (Pravetoni et al., 2012a). On day 48, rats were tailbled for titers. On day 55, rats were tested for antinociception as described in Experiment 2. On days 60, 61, 62, 63, 66,68 , and 70 , rats were tested in motor activity chambers with saline for the first three sessions and then challenged with oxycodone $(0.5 \mathrm{mg} / \mathrm{kg}$, s.c. $)$ for the next four sessions. Because $50 \mathrm{mg} / \mathrm{kg} \mathrm{XR}$ NTX completely blunted oxycodone-induced motor activity, rats were held for 1 month before retesting at a lower XR-NTX dose. Rats were vaccinated on days 83 and 104. Rats received a $5 \mathrm{mg} / \mathrm{kg}$ i.m. dose of XRNTX on study day 98 . On days $116,117,118,119,122,124$, and 126 rats, were tested in motor activity chambers with saline for the first three sessions and then challenged with oxycodone $(0.5 \mathrm{mg} / \mathrm{kg}$, s.c.) for the next four sessions.

Experiment 4: Effect of Low Doses of XR-NTX on Oxycodone-Induced Motor Activity and Thigmotaxis in Rats Immunized with OXY-KLH. The effect of a low dose of XR-NTX $(2.5 \mathrm{mg} / \mathrm{kg})$ on OXY-KLH vaccine behavioral efficacy was tested in rats to assess whether combining antagonist with vaccination would show increased efficacy compared with each individual treatment. To this end, a dose of XR-NTX (2.5 mg/kg, i.m.) was used because it produced a suboptimal reduction of oxycodone-induced motor activity. Rats received either saline or XR-NTX intramuscularly on days 0,42 , and 70 . Concurrently, these rats were immunized with either $100 \mu \mathrm{g}$ of the OXY-KLH vaccine or the unconjugated $\mathrm{KLH}$ on days $0,21,42$, and 72 in Freund's adjuvant as previously described (Pravetoni et al., 2012a). Groups $(n=8)$ were designated as follows: 1$) \mathrm{KLH}+$ saline, 2) $\mathrm{KLH}+$ XR-NTX, 3) OXY-KLH + saline, and 4) OXY-KLH + XR-NTX. On day 49 , rats were tailbled for titers. Rats were first tested for baseline motor activity after subcutaneous saline injections of $1 \mathrm{ml} / \mathrm{kg}$ on days 53,54 , and 55, which were followed by oxycodone-induced motor activity (as described above in Opioid-Induced Motor Activity and Thigmotaxis) after subcutaneous injections of $0.5 \mathrm{mg} / \mathrm{kg}$ oxycodone on days $56,59,61,63$, and 66 . To demonstrate increased efficacy of a combination with XR-NTX and vaccination, rats were subsequently challenged with $1.0 \mathrm{mg} / \mathrm{kg}$ oxycodone s.c. on testing days 73,75 , and 77 and $2.0 \mathrm{mg} / \mathrm{kg}$ on day 80 . All sessions recorded motor activity and thigmotaxis.

Experiment 5: Effect of Vaccination with OXY-KLH, Alone or in Combination with XR-NTX, on Oxycodone-Induced Motor Activity, Respiratory Depression, and Bradycardia. Rats received $2.25 \mathrm{mg} / \mathrm{kg}$ XR-NTX i.m. at 0 and 36 days. Concurrently, rats were immunized intramuscularly with either $60 \mu \mathrm{g}$ of the OXY-KLH vaccine or the unconjugated KLH administered at days 0,21 , and 42 . Aluminum hydroxide $(90 \mu \mathrm{g})$ was used as the adjuvant. Groups $(n=8)$ were as follows: 1) $\mathrm{KLH}$ + saline, 2) OXY-KLH + saline, and 3) OXY-KLH + XR-NTX. On day 49, rats were tailbled for titers. One week later, rats were given saline on three consecutive habituation sessions (days 53, 54, 


\section{Experiment 1}

Motor activity oxycodone $\quad$ Motor activity $_{0,0.25,0.5,0.75,1.0 \text { oxycodone }}$

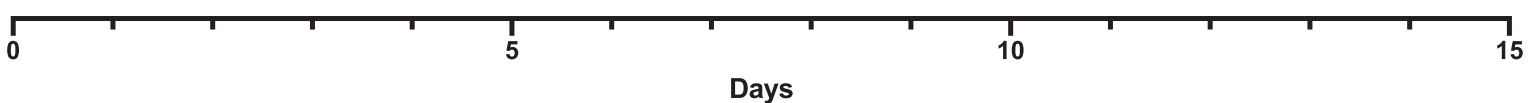

\section{Experiment 2}

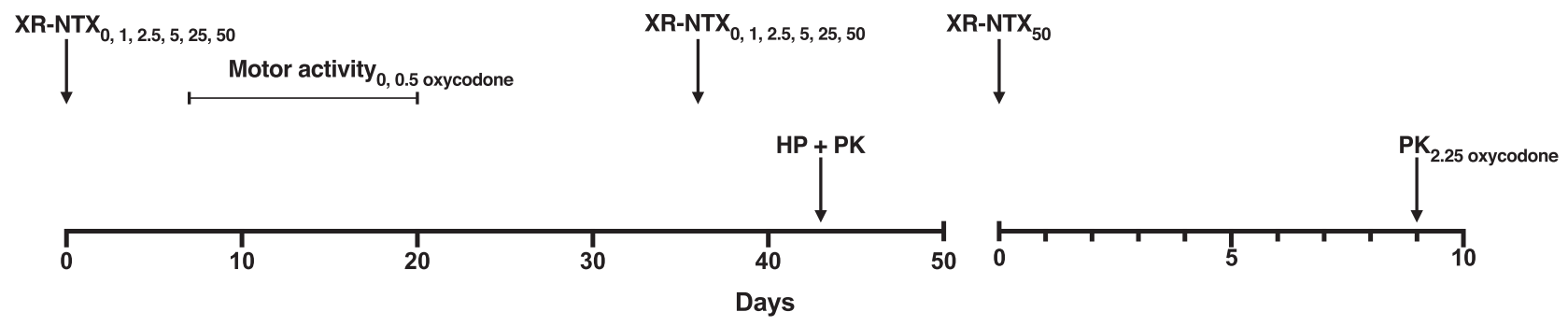

\section{Experiment 3}

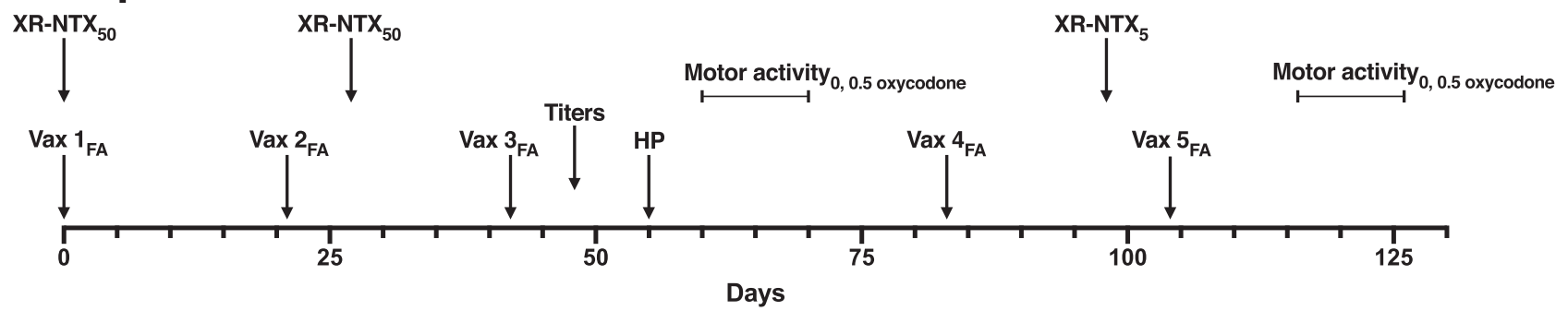

\section{Experiment 4}

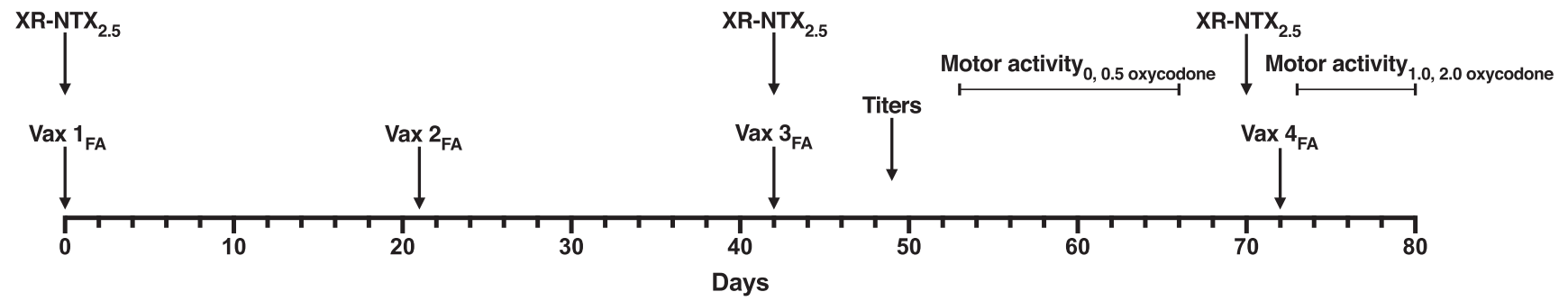

\section{Experiment 5}

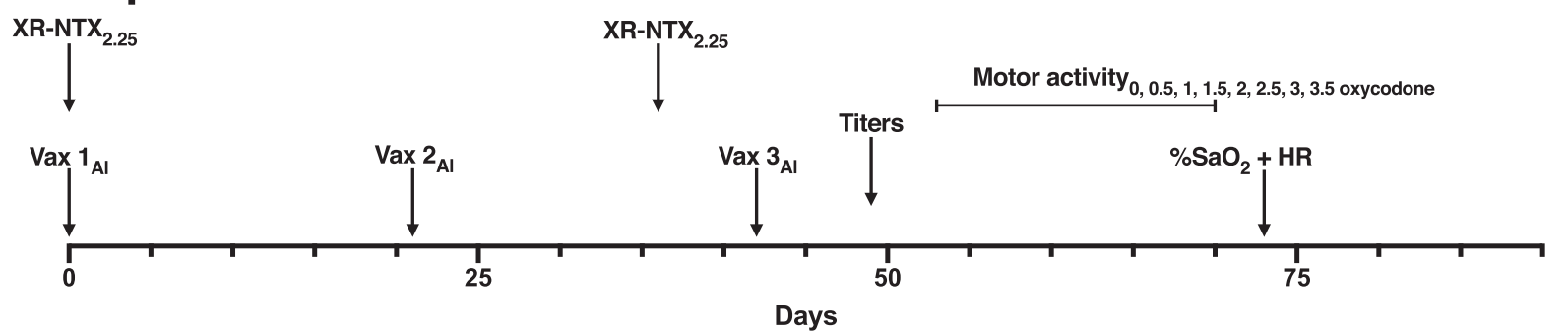

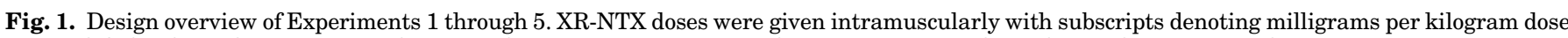

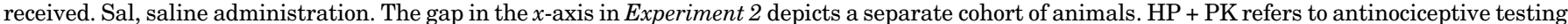

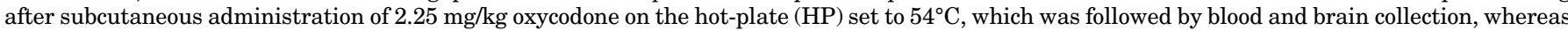

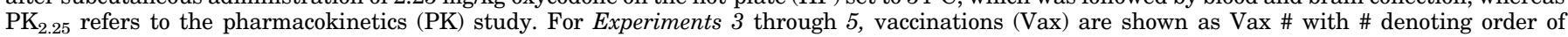

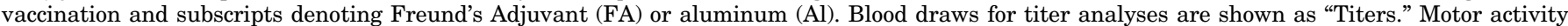

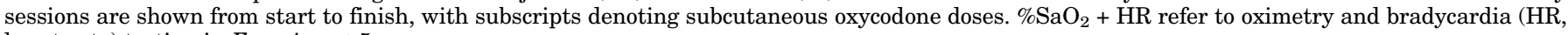
heart rate) testing in Experiment 5. 
and 55$)$. On testing days $56,59,61,63,66,68$, and 70 , rats were given escalating doses of oxycodone subcutaneously $(0.5,1,1.5,2,2.5,3$, and $3.5 \mathrm{mg} / \mathrm{kg}$, respectively) to track a dose-dependent variation in motor activity. On day 73, rats were tested for oxycodone-induced respiratory depression and bradycardia (as described above in Opioid-Induced Respiratory Depression and Bradycardia) 15 minutes after each dose of oxycodone that represented cumulative doses of 2.25, 4.5, and $9 \mathrm{mg} / \mathrm{kg}$. Oxygen saturation and bradycardia were also measured 30 minutes after administration of $9 \mathrm{mg} / \mathrm{kg}$ oxycodone.

\section{Statistical Analyses and Calculations}

One- or two-way ANOVA paired with Dunnett's or Bonferroni post hoc tests, respectively, were used to compare oxycodone antinociception, serum and brain distribution, and oximetry data across groups. Kruskal-Wallis test with Dunn's multiple comparisons post hoc test was used to compare antinociceptive effects between groups in Experiment 3. Pharmacokinetic parameters were compared between saline and XR-NTX-treated groups using unpaired $t$ tests, with Welch's correction being used to compare groups. All statistics were performed with GraphPad Prism (version 8.0; La Jolla, CA).

\section{Results}

Experiment 1: Oxycodone-Induced Motor Activity and Thigmotaxis Index in Nonimmunized Rats. The effect of varying doses of oxycodone on total traveled distance in motor activity chambers was characterized in the absence of other treatments to determine baseline values (Supplemental Fig. 1A). Two-way (treatment $\times$ time) repeated-measures ANOVA showed a significant effect of time $\left(\mathrm{F}_{(6,162)}=32.92 ; P<0.0001\right)$ and interaction $\left(\mathrm{F}_{(24,162)}=\right.$ $3.56 ; P<0.0001)$ but not treatment $\left(\mathrm{F}_{(4,162)}=2.16\right)$. The 0.25 and $0.50 \mathrm{mg} / \mathrm{kg}$ oxycodone doses did not significantly increase motor activity compared with the saline control group. The $0.75 \mathrm{mg} / \mathrm{kg}$ oxycodone dose increased activity on test day $7\left(\mathrm{t}_{(4)}=3.42 ; P<0.05\right)$ and days 9 and 11 (respectively, $\mathrm{t}_{(4)}=4.61$ and $4.48 ; P<0.001$ ). The $1.0 \mathrm{mg} / \mathrm{kg}$ oxycodone dose increased motor activity on test days 9 and $11\left(\mathrm{t}_{(4)}=3.53\right.$ and $\left.3.49 ; P<0.05\right)$ compared with saline controls; however, this dose did not further increase motor activity compared with $0.75 \mathrm{mg} / \mathrm{kg}$. Based on this preliminary study, subsequent testing of the efficacy of XRNTX, vaccination, or their combination in blocking oxycodone-induced motor activity started from a midrange dose of $0.5 \mathrm{mg} / \mathrm{kg}$ oxycodone. Thigmotaxis index increased as a function of the oxycodone dose (Supplemental Fig. 1B), with one-way ANOVA showing a significant effect of treatment $\left(\mathrm{F}_{(4,27)}=3.291 ; P<0.001\right)$ and a significant increase after $0.75 \mathrm{mg} / \mathrm{kg}$ oxycodone dose compared with control $(\mathrm{q}=4.94 ; P<0.05)$.

Experiment 2: Effect of XR-NTX on Oxycodone-Induced Motor Activity, Thigmotaxis Index, Antinociception, and Oxycodone Distribution in Nonvaccinated Naïve Rats. Administration of XR-NTX dose-dependently reduced oxycodone-induced motor activity (Fig. 2A). Two-way (treatment $\times$ time) repeated-measures ANOVA showed a significant effect of time $\left(\mathrm{F}_{(7,406)}=54.98 ; P<0.0001\right)$, treatment $\left(\mathrm{F}_{(5,58)}=\right.$ $9.45 ; P<0.0001)$, and interaction $\left(\mathrm{F}_{(35,406)}=6.24 ; P<0.001\right)$ on oxycodone-induced activity. XR-NTX significantly decreased oxycodone-induced motor activity at all doses at and above $5 \mathrm{mg} / \mathrm{kg}(\mathrm{t}=4.01-6.97 ; P<0.01)$. One-way ANOVA showed a significant effect of treatment $\left(\mathrm{F}_{(5,23.69}=14.44\right.$;
$P<0.01$ ) on thigmotaxis index. All doses of XR-NTX, except $1.0 \mathrm{mg} / \mathrm{kg}$, were associated with a significant reduction (respectively, $2.5-50 \mathrm{mg} / \mathrm{kg}, \mathrm{t}=4.84-7.23 ; P<0.001$ ) of the thigmotaxis index compared with saline control (Fig. 2B). XR-NTX administration reduced oxycodone antinociception (Fig. 2C). One-way ANOVA showed a significant effect of treatment $\left(\mathrm{F}_{(5,58)}=22.43 ; P<0.0001\right)$ on nociception in the hot-plate test. All doses of XR-NTX, except $1.0 \mathrm{mg} / \mathrm{kg}$, significantly reduced oxycodone antinociception $(2.5 \mathrm{mg} / \mathrm{kg}, \mathrm{q}=2.7$; $P<0.05$; and $5-50 \mathrm{mg} / \mathrm{kg}, \mathrm{q}=6.96-7.5 ; P<0.0001$, respectively).

One-way ANOVA showed a significant effect of treatment on serum oxycodone distribution $\left(\mathrm{F}_{(3,28)}=7.51 ; P<0.001\right.$, Fig. 2D) and brain $\left(\mathrm{F}_{(3,28)}=5.37 ; P<0.01\right.$, Fig. $\left.2 \mathrm{E}\right)$. The two highest doses of XR-NTX (25 and $50 \mathrm{mg} / \mathrm{kg}$ ) significantly reduced oxycodone in serum ( $\mathrm{q}=3.83$ and $4.29 ; P<0.01$ and $P<0.001$, respectively) and brain $(\mathrm{q}=2.74$ and $3.61 ; P<0.05$ and $P<0.01$, respectively) 30 minutes after subcutaneous injection of $2.25 \mathrm{mg} / \mathrm{kg}$ oxycodone.

In rats, pretreatment with $50 \mathrm{mg} / \mathrm{kg}$ XR-NTX significantly reduced $\mathrm{c}_{\max }, \mathrm{AUC}$, and $\mathrm{Cl} / \mathrm{F}$ after a $2.25 \mathrm{mg} / \mathrm{kg}$, s.c. oxycodone challenge compared with saline pretreated rats (Table 1). Two-way ANOVA showed an effect of time $\left(\mathrm{F}_{(5,63)}=24.16 ; P<\right.$ 0.0001 ) but no effect on treatment or interaction (Fig. 2F). No differences between groups were detected at any single time point.

Experiment 3: Effect of High Doses of XR-NTX on Oxycodone-Induced Motor Activity in Rats Vaccinated with OXY-KLH. Oxycodone-specific antibody titers in OXY$\mathrm{KLH}-$ and OXY-KLH + XR-NTX (50 mg/kg)-treated rats were $41 \pm 16 \times 10^{3}$ and $84 \pm 52 \times 10^{3}$, respectively (mean \pm S.D.). There were no differences in titers between groups (Supplemental Fig. 3). Only XR-NTX and OXY-KLH + XRNTX showed reduction in oxycodone-induced antinociception on the hot-plate (Supplemental Fig. 4). After subcutaneous administration of $0.5 \mathrm{mg} / \mathrm{kg}$ oxycodone, two-way (treatment $\times$ time) repeated-measures ANOVA showed a significant effect on time $\left(\mathrm{F}_{(1.954,54.70)}=24.08 ; P<0.0001\right)$, treatment $\left(\mathrm{F}_{(3,28)}=\right.$ 20.76; $P<0.0001)$, and interaction $\left(\mathrm{F}_{(18,168)}=8.74 ; P<\right.$ 0.0001) (Fig. 3A) on motor activity. Vaccination with OXY$\mathrm{KLH}$ alone had no effect on motor activity compared with KLH-vaccinated rats. Rats treated with XR-NTX + OXY-KLH showed a significantly reduction in oxycodone-induced motor activity on every test day $[\mathrm{t}(43$ days $)=3.464, \mathrm{t}(46$ days $)=$ $3.454, \mathrm{t}(48$ days $)=5.010, \mathrm{t}(50$ days $)=3.520 ; P<0.05]$ compared with saline control as well as after XR-NTX alone $[\mathrm{t}(43$ days $)=4.057, \mathrm{t}(46$ days $)=3.891, \mathrm{t}(48$ days $)=5.382, \mathrm{t}(50$ days $)=4.176 ; P<0.05]$.

After 1 month, rats were revaccinated and received a lower dose of XR-NTX $(5 \mathrm{mg} / \mathrm{kg})$. After subcutaneous administration of $0.5 \mathrm{mg} / \mathrm{kg}$ oxycodone, two-way (treatment $\times$ time) repeatedmeasures ANOVA showed a significant effect on time $\left(\mathrm{F}_{(6,167)}\right.$ $=19.10 ; P<0.0001)$, treatment $\left(\mathrm{F}_{(3,28)}=3.377 ; P<0.05\right)$, and interaction $\left(\mathrm{F}_{(18,167)}=2.315 ; P<0.01\right)$ (Fig. 3B). Vaccination with OXY-KLH alone had no effect on motor activity compared with KLH-vaccinated rats. Rats treated with XR-NTX plus OXY-KLH showed a significantly reduction in oxycodoneinduced motor activity on every test day [ $\mathrm{t}(119$ days $)=$ $3.632, \mathrm{t}(122$ days $)=2.937, \mathrm{t}(124$ days $)=2.626, \mathrm{t}(126$ days $)=$ $2.727 ; P<0.05]$ compared with saline control as well as after XR-NTX alone on 2 days $[\mathrm{t}(122$ days $)=2.640, \mathrm{t}(124$ days $)=$ $2.839 ; P<0.05]$. 
A Oxycodone $(0.5 \mathrm{mg} / \mathrm{kg}, \mathrm{sc})$

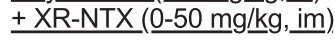

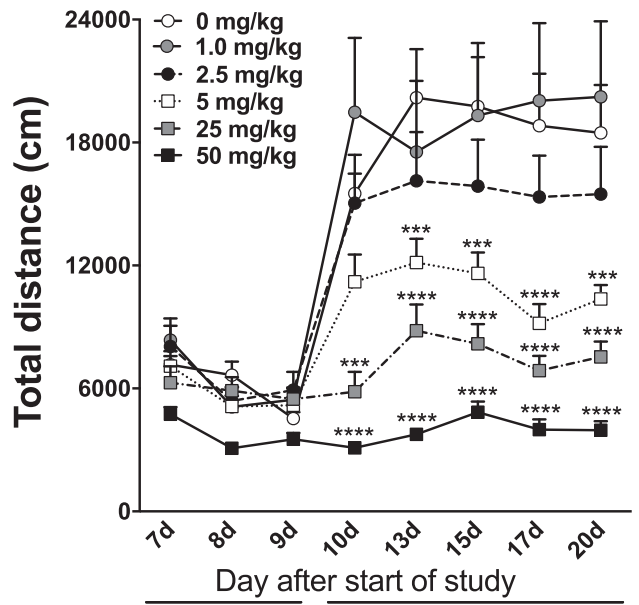

Saline Oxycodone

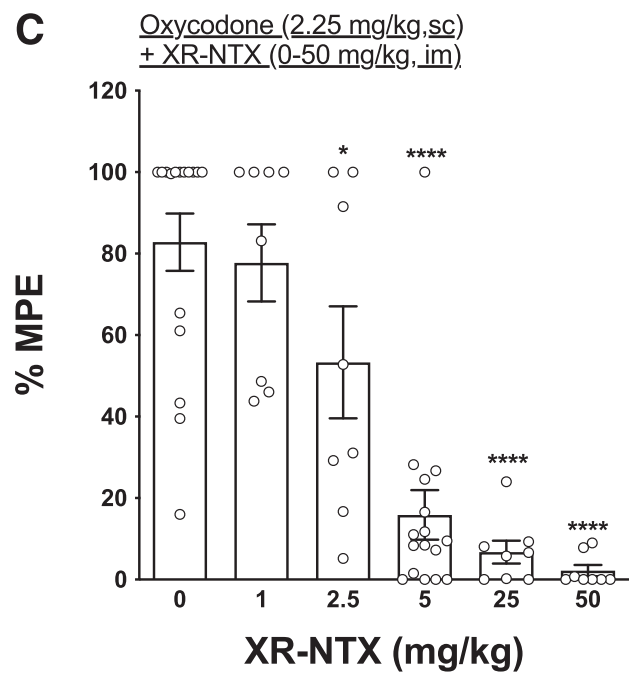

E

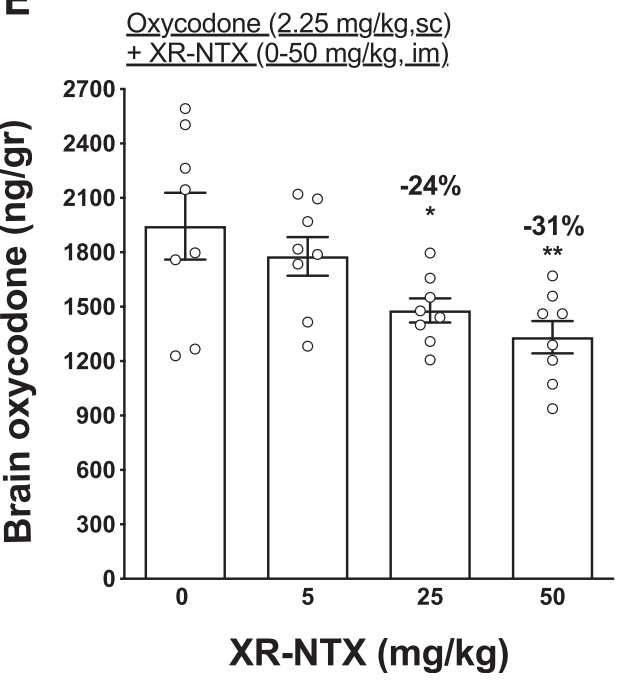

B $\quad$ Oxycodone $(0.5 \mathrm{mg} / \mathrm{kg}, \underline{\mathrm{sc}})$

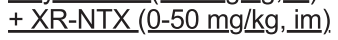

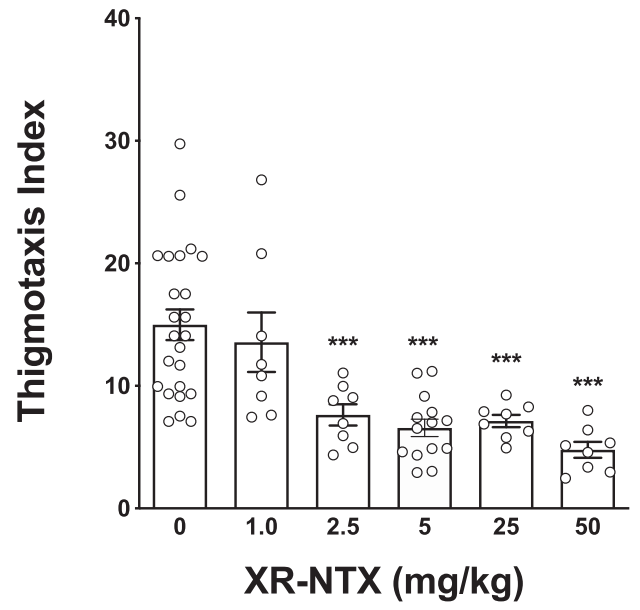

D Oxycodone $(2.25 \mathrm{mg} / \mathrm{kg}, \mathrm{sc})$

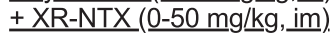

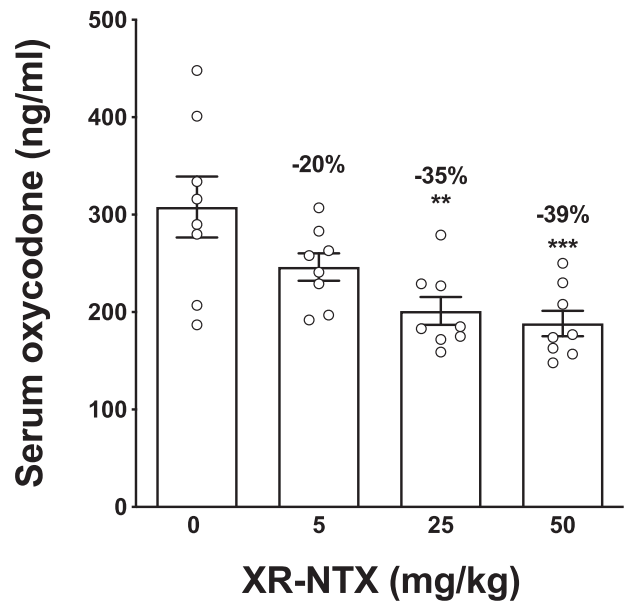

$\mathbf{F}$

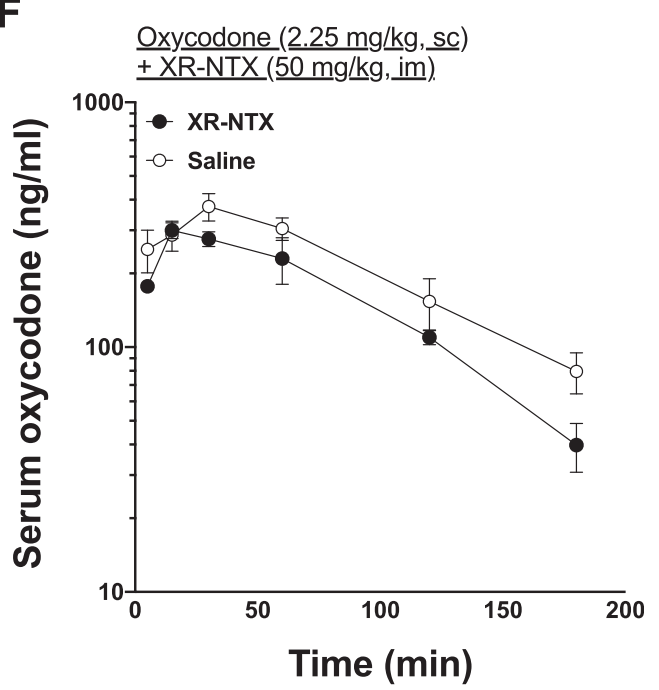

Fig. 2. Effect of XR-NTX on oxycodone-induced motor activity, thigmotaxis index, antinociception, and distribution in naïve rats. Rats $(n=8$ each group) received $0,1,2.5,5,25$, or $50 \mathrm{mg} / \mathrm{kg}$ XR-NTX (i.m.). (A) Rats then received $0.5 \mathrm{mg} / \mathrm{kg}$ oxycodone s.c, and their activity was measured for $90 \mathrm{minutes}$. (B) Thigmotaxis measurements were recorded during motor activity. (C) Antinociception was measured using the hot-plate (set to $54^{\circ} \mathrm{C}$ ) 30 minutes after subcutaneous administration of $2.25 \mathrm{mg} / \mathrm{kg}$ oxycodone. (D and E) Serum and brain oxycodone levels were measured after antinociception. (F) Separately, nonvaccinated naïve rats $(n=8)$ were administered either $50 \mathrm{mg} / \mathrm{kg}$ XR-NTX i.m. or saline, and blood was collected at 15, 30, 60, 120, and 180 minutes. Data are expressed as mean \pm S.E.M. Thigmotaxis index was calculated as the ratio of the distance traveled in the external area to the one traveled in the center. Two-way ANOVA with Bonferroni post-test (A and F) or one-way ANOVA using Dunnett's multiple comparisons test (B-E) was used to compare groups to saline. ${ }^{*} P<0.05 ; * * P<0.01$; ${ }^{* * * P}<0.001$; ${ }^{* * * *} P<0.0001$ from saline control. MPE, maximum possible effect. 
TABLE 1

Effect of XR-NTX on pharmacokinetic parameters of oxycodone

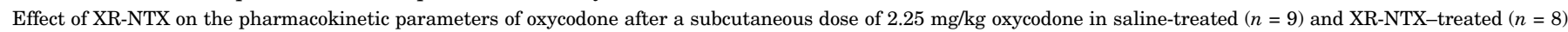
rats. Data are expressed as mean \pm S.D.

\begin{tabular}{|c|c|c|c|c|}
\hline Parameter & Saline & XR-NTX & $\mathrm{t}$ Value & $P$ Value \\
\hline Half-life (h) & $1.04 \pm 0.48$ & $0.94 \pm 0.40$ & 0.4525 & 0.6574 \\
\hline $\mathrm{t}_{\max }(\mathrm{h})$ & $0.56 \pm 0.27$ & $0.34 \pm 0.13$ & 2.078 & 0.0604 \\
\hline$c_{\max }(n g / m l)$ & $440.8 \pm 112.1$ & $309.1 \pm 64.6^{*}$ & 3.006 & 0.0101 \\
\hline $\mathrm{AUC}_{0-\mathrm{inf}}\left(\mathrm{h}^{*} \mathrm{ng} / \mathrm{ml}\right)$ & $799.7 \pm 217.0$ & $525.4 \pm 158.5^{* *}$ & 2.998 & 0.0093 \\
\hline MRT (h) & $1.71 \pm 0.72$ & $1.42 \pm 0.54$ & 0.9395 & 0.3627 \\
\hline $\mathrm{Vd} / \mathrm{F}(\mathrm{l} / \mathrm{kg})$ & $4.33 \pm 1.92$ & $5.81 \pm 1.47$ & 1.1806 & 0.0913 \\
\hline $\mathrm{Cl} / \mathrm{F}(\mathrm{l} / \mathrm{h}$ per kilogram $)$ & $2.99 \pm 0.77$ & $4.61 \pm 1.27 * *$ & 3.143 & 0.0091 \\
\hline
\end{tabular}

Estimates for pharmacokinetic parameters include half-life; $\mathrm{AUC}_{0 \text {-inf }}, \mathrm{AUC}$ from zero to infinity; $\mathrm{MRT}$, mean residence time; $\mathrm{t}_{\mathrm{max}}$, time to reach $\mathrm{c}_{\mathrm{max}} ; \mathrm{Vd} / \mathrm{F}$, volume of distribution over the fraction absorbed; $\mathrm{Cl} / \mathrm{F}$, clearance over the fraction absorbed.

${ }^{*} P<0.05 ; * * P<0.01$ compared with saline treatment.

Experiment 4: Effect of Low Doses of XR-NTX on Oxycodone-Induced Activity and Thigmotaxis in Rats Immunized with OXY-KLH. Oxycodone-specific antibody titers in OXY-KLH and OXY-KLH + XR-NTX (2.5 mg/kg) were $207 \pm 69 \times 10^{3}$ and $98 \pm 80 \times 10^{3}$, respectively (mean \pm S.D.), which were significantly different $(P<0.05$, Supplemental Fig. 3). In rats repeatedly challenged with $0.5 \mathrm{mg} / \mathrm{kg}$ oxycodone s.c. (Fig. 4A), two-way (treatment $\times$ time) repeatedmeasures ANOVA showed a significant effect on time $\left(\mathrm{F}_{(7,189)}\right.$ $=46.54 ; P<0.0001)$, treatment $\left(\mathrm{F}_{(3,27)}=15.21 ; P<0.0001\right)$, and interaction $\left(\mathrm{F}_{(21,189)}=9.2 ; P<0.001\right)$. Vaccination with OXY-KLH alone and in combination with XR-NTX significantly reduced oxycodone-induced motor activity compared with KLH controls $(P<0.001)$.

Subsequently, on testing days 73-77, rats were challenged with $1.0 \mathrm{mg} / \mathrm{kg}$ oxycodone s.c. (Fig. 4B). Two-way (treatment $\times$ time) repeated-measures ANOVA showed a significant main effect of treatment $\left(\mathrm{F}_{(3,26)}=4.17 ; P<0.05\right)$. Treatment with OXY-KLH combined with XR-NTX reduced oxycodoneinduced motor activity compared with $\mathrm{KLH}$ controls on testing days 73 and $75[\mathrm{t}(73$ days $)=3.85 ; P<0.01$, $\mathrm{t}(75$ days $)=3.27$; $P<0.05$, respectively]. No other differences were observed. There was no effect of vaccine or XR-NTX on oxycodoneinduced thigmotaxis (Fig. 4C). Rats were then challenged with a final dose of $2 \mathrm{mg} / \mathrm{kg}$ oxycodone, s.c. but no differences were detected between groups (Fig. 4D).

Experiment 5: Effect of Vaccination with OXY-KLH, Alone or in Combination with XR-NTX, on Oxycodone-Induced Motor Activity, Respiratory Depression, and Bradycardia. Oxycodone-specific antibody titers in OXY-KLH and OXY-KLH + XR-NTX $(2.25 \mathrm{mg} / \mathrm{kg})$ were $203 \pm 98 \times 10^{3}$ and $136 \pm 76 \times 10^{3}$, respectively (mean \pm S.D.). There were no differences in titers between groups (Supplemental Fig. 3). Rats ( $n=8$ each group) were first given saline on three consecutive habituation sessions. On alternate sessions afterward rats were administered 0.5, 1, 1.5, 2, 2.5, 3, and $3.5 \mathrm{mg} / \mathrm{kg}$ of oxycodone (s.c.) to track dose-dependent variations in motor activity brought on by oxycodone. Twoway (treatment $\times$ time) repeated-measures ANOVA showed a significant effect of time $\left(\mathrm{F}_{(7,147)}=12.23\right)$ but not of treatment and interaction on oxycodone-induced activity (Fig. 5A). Because of the motor depressive effects of oxycodone at $2.5 \mathrm{mg} / \mathrm{kg}$ and above, the data were split and examined from 0 to $2 \mathrm{mg} / \mathrm{kg}$ oxycodone dosing (Supplemental Fig. 5 shows motor activity up to $3.5 \mathrm{mg} / \mathrm{kg}$ ). Two-way (treatment $\times$ time) repeated-measures ANOVA showed a significant effect of time
$\left(\mathrm{F}_{(4,84)}=24.42\right)$ but not of treatment and interaction on oxycodone-induced activity. Combination of XR-NTX and OXY-KLH vaccine showed a significant effect on reducing oxyocodone-induced motor activity after $1.0 \mathrm{mg} / \mathrm{kg}$ oxycodone administration ( $\mathrm{t}=3.08 ; P<0.01)$ compared with $\mathrm{KLH}$ control. No other differences were observed.

Three days after motor activity testing, rats were tested for oxycodone-induced respiratory depression and bradycardia 15 minutes after each dose of oxycodone that represented cumulative doses of $2.25,4.5$, and $9 \mathrm{mg} / \mathrm{kg}$. Two-way (treatment $\times$ time) repeated-measures ANOVA showed a significant effect of oxycodone dose on $\% \mathrm{SaO}_{2}\left(\mathrm{~F}_{(4,104)}=25.43 ; P<\right.$ $0.0001)$ and heart rate $\left(\mathrm{F}_{(4,104)}=7.316 ; P<0.0001\right)$. Two-way (treatment $\times$ time) repeated-measures ANOVA also showed a significant effect of treatment on $\% \mathrm{SaO}_{2}\left(\mathrm{~F}_{(2,104)}=14.36\right.$; $P<0.0001)$ and heart rate $\left(\mathrm{F}_{(2,104)}=9.283 ; P<0.001\right)$. There was no interaction significance for either oxycodone dose or treatment. Combination of XR-NTX and OXY-KLH showed higher \% $\mathrm{SaO}_{2}$ levels after oxycodone administration of $4.5 \mathrm{mg} / \mathrm{kg}(\mathrm{t}=2.841 ; P<0.05), 9_{15}$ minutes $\mathrm{mg} / \mathrm{kg}(\mathrm{t}=4.229$; $P<0.001)$, and 930 minutes $\mathrm{mg} / \mathrm{kg}(\mathrm{t}=4.091 ; P<0.001)$ compared with KLH control (Fig. 5B). Both KLH and OXY$\mathrm{KLH}$ showed reduced $\% \mathrm{SaO}_{2}$ levels at $4.5 \mathrm{mg} / \mathrm{kg}(\mathrm{t}=3.981, \mathrm{t}$ $=4.116, \mathrm{t}=5.102 ; P<0.05), 9_{15}$ minutes $\mathrm{mg} / \mathrm{kg}(\mathrm{t}=3.397, \mathrm{t}=$ $5.903, \mathrm{t}=7.427 ; P<0.05)$, and $9_{30 \text { minutes }} \mathrm{mg} / \mathrm{kg}(\mathrm{t}=3.981, \mathrm{t}=$ 4.116, $\mathrm{t}=5.102 ; P<0.05)$ compared with baseline levels, whereas combination of XR-NTX and OXY-KLH showed reduced $\% \mathrm{SaO}_{2}$ levels only at $9_{15}$ minutes $\mathrm{mg} / \mathrm{kg}(\mathrm{t}=3.589$; $P<0.05)$.

Combination of XR-NTX and OXY-KLH reduced the extent of bradycardia induced by $9 \mathrm{mg} / \mathrm{kg}$ oxycodone $(\mathrm{t}=2.917, \mathrm{t}=$ 2.881; $P<0.05,15$ and 30 minutes after injection of the drug, respectively) compared with the $\mathrm{KLH}$ control and compared with OXY-KLH alone ( $\mathrm{t}=3.358 ; P<0.01$ ) (Fig. 5C). Only KLH alone showed reduced $\% \mathrm{SaO}_{2}$ levels at $9_{15 \text { minutes }} \mathrm{mg} / \mathrm{kg}(\mathrm{t}=$ $4.281 ; P<0.05)$ and at $9_{30 \text { minutes }} \mathrm{mg} / \mathrm{kg}(\mathrm{t}=3.587 ; P<0.05)$ compared with baseline levels.

\section{Discussion}

This study provided preclinical proof of concept for combination therapy against OUD by coadministration of an FDAapproved extended-release antagonist formulation and a candidate vaccine against the prescription opioid oxycodone. The major findings were: 1) XR-NTX blocked oxycodoneinduced motor activity and oxycodone antinociception in rats 
A Oxycodone $(0.5 \mathrm{mg} / \mathrm{kg}, \mathrm{sc})$ + XR-NTX $(50 \mathrm{mg} / \mathrm{kg}, \underline{\mathrm{im}})$

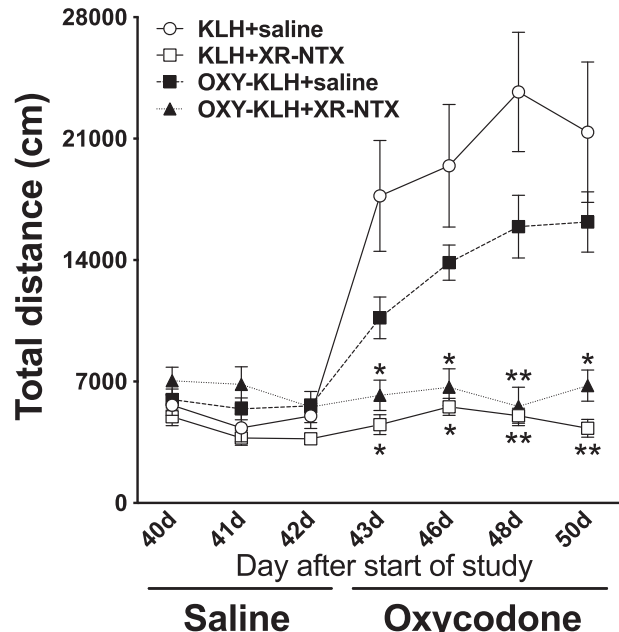

B $\quad$ Oxycodone $(0.5 \mathrm{mg} / \mathrm{kg}, \mathrm{sc})$

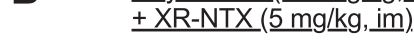

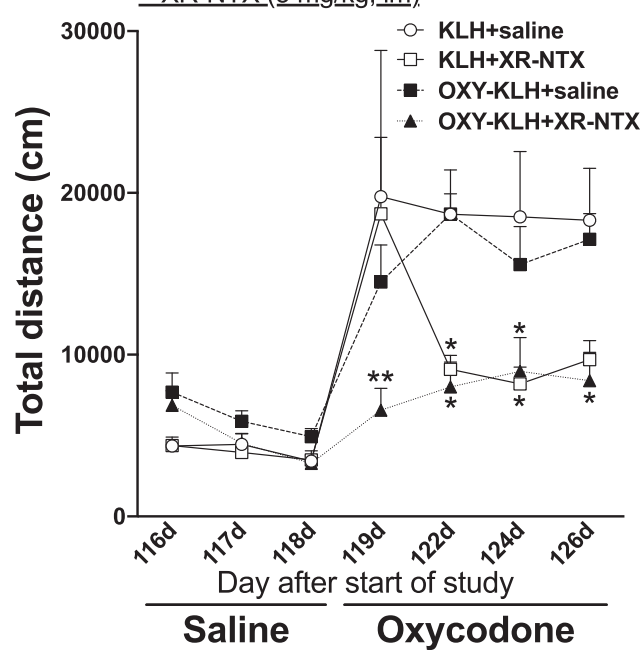

Fig. 3. Effect of high dose of extended-release naltrexone on oxycodoneinduced motor activity in rats immunized with OXY-KLH. (A) Rats ( $n=8$ / group) received either saline or $50 \mathrm{mg} / \mathrm{kg}$ XR-NTX i.m. on days 0 and 27 and immunized with either $100 \mu \mathrm{g}$ of the OXY-KLH vaccine or the unconjugated KLH administered on days 0, 21, and 42 in Freund's adjuvant and tested in motor activity chambers. (B) Rats were then vaccinated on days 83 and 104. Rats received a lower XR-NTX dose of $5 \mathrm{mg} / \mathrm{kg}$ i.m. on day 98 . Rats were subsequently tested in motor activity chambers after subcutaneous doses of saline and $0.5 \mathrm{mg} / \mathrm{kg}$ oxycodone. Data are expressed as mean \pm S.E.M. Two-way ANOVA with Bonferroni post-test was performed to compare groups to controls. ${ }^{*} P<0.05$; ${ }^{* *} P<$ 0.01 , from KLH + saline.

in a dose-dependent manner, 2) XR-NTX reduced distribution of oxycodone to serum and brain as well as the AUC, 3) XRNTX minimally interfered with the OXY-KLH vaccine ability to induce oxycodone-specific serum antibodies, and 4) the combination of XR-NTX with OXY-KLH showed greater effect than each treatment alone in reducing motor activity and anxiolytic effects as well as protecting against reduction of $\% \mathrm{SaO}_{2}$ and heart rate induced by repeated doses of oxycodone in rats. Together, these data support the combination of antiopioid vaccines with XR-NTX for the treatment of OUD and possibly prevention of opioid-induced toxicity associated with fatal overdose (e.g., respiratory depression).
To develop an animal model to test the effect of combining antiopioid vaccines with XR-NTX and compare their efficacy to each individual treatment, the effects of XR-NTX on oxycodone-induced motor activity and hot-plate analgesia were tested in rats. Very low doses of naltrexone (naltrexone:oxycodone dose ratio of $1: 10^{8}$ ) have been shown to enhance the motor activity induced by oxycodone (Leri and Burns, 2005). Higher naltrexone doses used in the current study (naltrexone:oxycodone dose ratio between 1:1.5 and 1:25) reduced oxycodone-induced locomotor activity in a dosedependent manner. Yet, differences in experimental design complicate interpretation of preclinical data across studies. Abstinence from opioid use after XR-NTX has been demonstrated in humans with doses of $380 \mathrm{mg}[5.4 \mathrm{mg} / \mathrm{kg}$ in a $70-\mathrm{kg}$ human, (Nunes et al., 2015)], suggesting that these higher XR-NTX doses, as those used in the current study, are more typical of those used clinically. Combining XR-NTX and vaccine concurrently so that lower doses of both could be used and side effects minimized would be the ultimate goal.

XR-NTX dose-dependently decreased oxycodone-induced antinociception in the hot-plate test. Although this effect has not previously been demonstrated using oxycodone, similar effects have been shown for XR-NTX against morphine, fentanyl, and hydrocodone (Bartus et al., 2003; Dean et al., 2008). In these previous studies, very large doses of XR-NTX $(50 \mathrm{mg} / \mathrm{kg}$ ) were used to demonstrate that XR-NTX can block antinociception. The current data extend this range of efficacy to much lower XR-NTX doses (down to $2.5-5 \mathrm{mg} / \mathrm{kg}$ ). However, different opioids may require more or less XR-NTX depending on their relative potency at opioid receptors.

Unexpectedly, XR-NTX dose-dependently decreased distribution of oxycodone to serum and brain in rats. A second experiment showed that XR-NTX reduces the $c_{\max }$, clearance, and AUC after subcutaneous administration of oxycodone. These findings suggest that XR-NTX alters the pharmacokinetics of oxycodone and the overall exposure of oxycodone in rats. It is not clear why XR-NTX produces these effects. Although it is possible that XR-NTX affected oxycodone absorption from the injection site into blood in this study, it is unlikely because XR-NTX and oxycodone were administered at different sites and times. Another possibility is that naltrexone interfered with analysis of oxycodone; however, this was not seen in preliminary in vitro studies. Although XRNTX could have increased oxycodone clearance, accounting for both serum and brain oxycodone levels being lower in animals receiving naltrexone, we are aware of no reports of such an effect. The reduced oxycodone brain concentration in presence of naltrexone could be due to an effect of naltrexone on opioid transport across the blood brain barrier (BBB). For instance, it has been shown that oxycodone, a cationic opioid agonist, is actively transported across the BBB (Bostrom et al., 2006), although it is not clear whether oxycodone is a substrate for the well-characterized P-glycoprotein transporter (Bostrom et al., 2005) or for another organic cation transporter (Okura et al., 2008; Sadiq et al., 2011). Interactions on transport across the BBB have been shown between oxycodone and other central nervous system-acting drugs (Nakazawa et al., 2010). However, naltrexone has been demonstrated to not have any interaction with P-glycoprotein transporters, so it is unlikely that naltrexone affected these transporters to affect oxycodone pharmacokinetics (Metcalf et al., 2014). Despite the unknown specific mechanism of this pharmacokinetic 
A

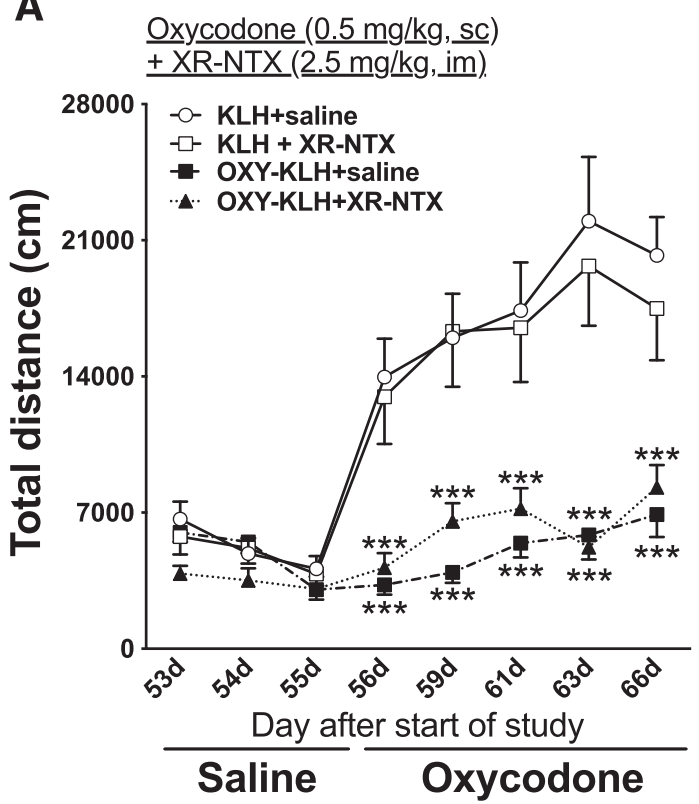

B

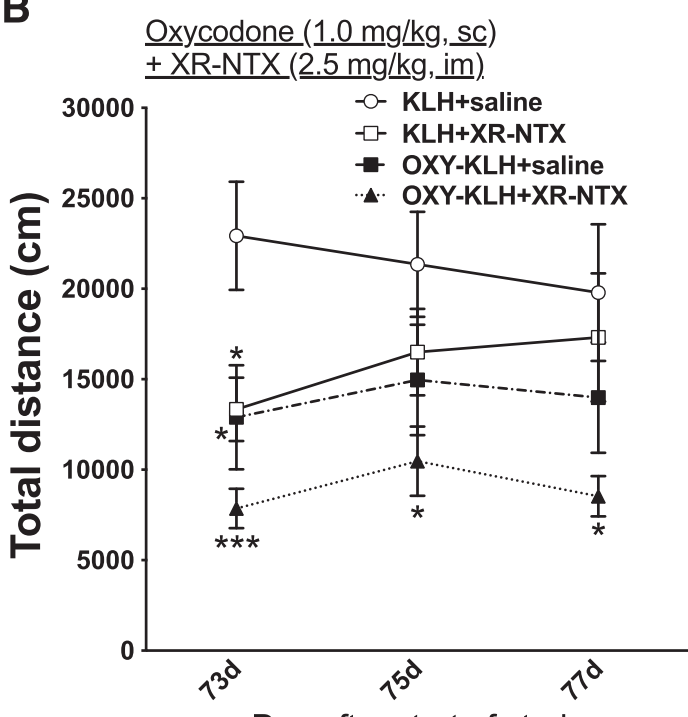

Day after start of study

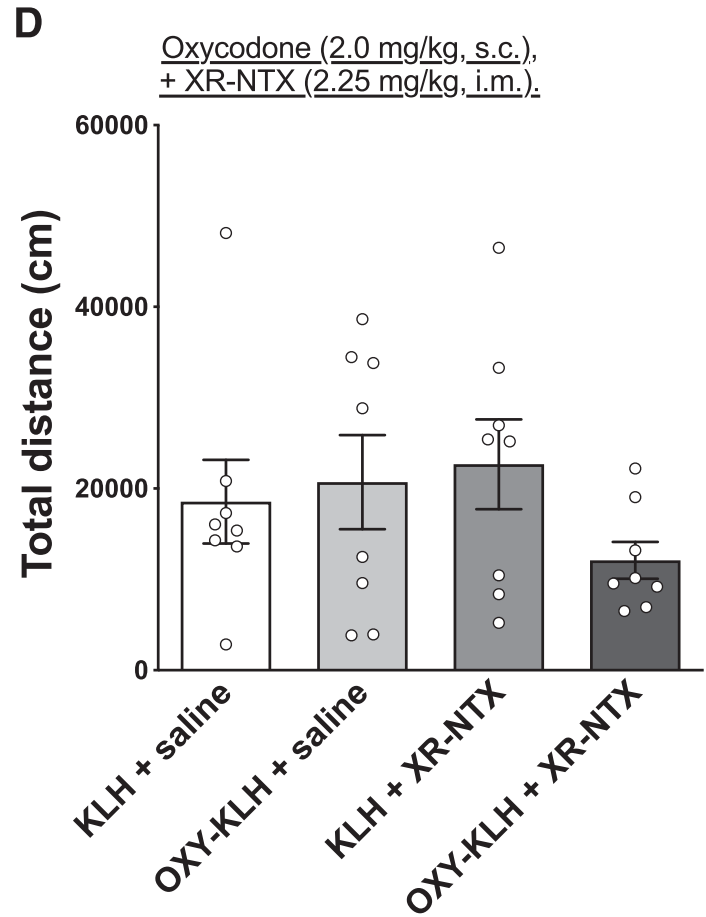

Fig. 4. Effect of low dose of extended-release naltrexone on oxycodone-induced activity and thigmotaxis in rats immunized with OXY-KLH. Rats received either saline or XR-NTX intramuscularly on days 0, 42, and 70. Concurrently, rats were immunized with either $100 \mu \mathrm{g}$ of the OXY-KLH or KLH on days $0,21,42$, and 72 in Freund's adjuvant. (A) Rats were tested in motor activity chambers after subcutaneous doses of saline and $0.5 \mathrm{mg} / \mathrm{kg}$ oxycodone. Then, rats received $1.0 \mathrm{mg} / \mathrm{kg}$ oxycodone s.c. and (B) motor activity, and (C) thigmotaxis were measured. (D) Motor activity was measured after a subcutaneous challenge of $2.0 \mathrm{mg} / \mathrm{kg}$ oxycodone. Two-way ANOVA with Bonferroni post-test or one-way ANOVA using Dunnett's multiple comparisons test was performed to compare with KLH controls. Data are expressed as mean \pm S.E.M. $* P<0.05 ; * * * P<0.001$ different from KLH + saline control and from KLH + XR-NTX.

interaction, XR-NTX did not impair the efficacy of vaccination for blocking oxycodone-induced motor activity, which was the main focus of this study.

XR-NTX significantly lowered oxycodone-specific antibody titers only in selected experiments. XR-NTX's effect on antibody titers was less evident when OXY-KLH was administered intramuscularly in aluminum adjuvant. Similarly, the immunomodulatory properties of naltrexone (or its XR-NTX formulation) seemed dose-dependent because this effect was significant at a low dose of XR-NTX $(2.5 \mathrm{mg} / \mathrm{kg})$ but not after a high dose $(50 \mathrm{mg} / \mathrm{kg})$. In a previously published study, XRNTX did not interfere with the ability of OXY-KLH to induce antibodies in rats (Raleigh et al., 2017). In contrast, naltrexone has been shown to have immunostimulant activity in one 


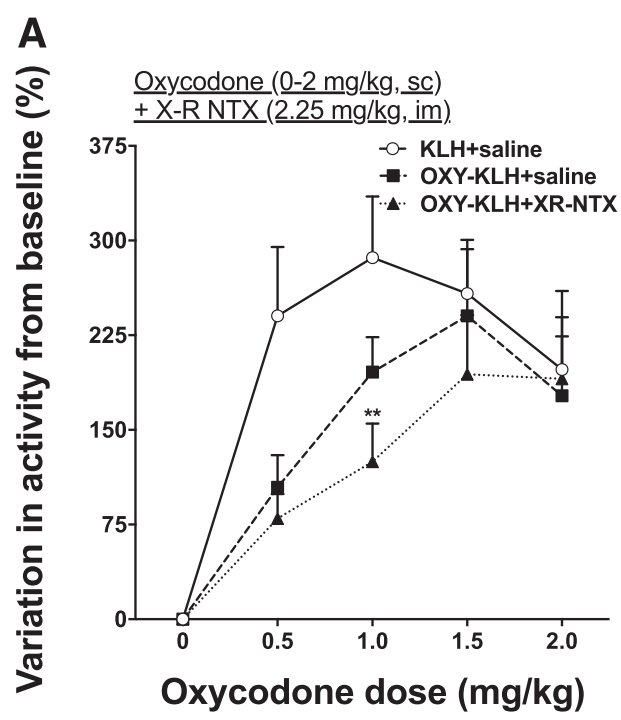

B Oxycodone $(\underline{0-9 \mathrm{mg} / \mathrm{kg}, \mathrm{sc})}$
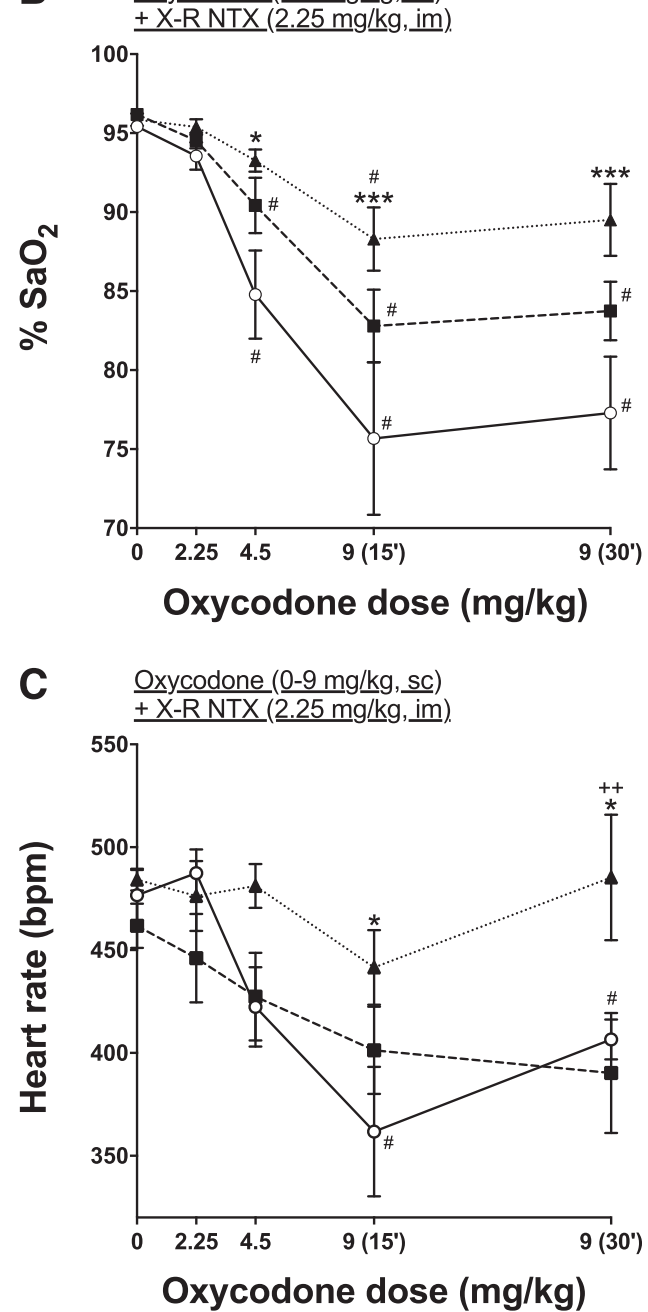

Fig. 5. Dose-dependent effect of oxycodone on motor activity, oxygen saturation, and heart rate of rats treated with $\mathrm{OXY}-\mathrm{KLH}$ vaccine, alone or in combination with XR-NTX. Rats ( $n=8$ /group) received either saline or XR-NTX intramuscularly on days 0,42 , and 70. Concurrently, rats were immunized with either $100 \mu \mathrm{g}$ of the OXY-KLH or KLH on days 0,21 , and 42. Aluminum hydroxide $(90 \mu \mathrm{g})$ was used as the adjuvant. (A) Motor activity was measured after saline or $0.5,1.0,1.5$, and $2.0 \mathrm{mg} / \mathrm{kg}$ of oxycodone subcutaneously. (B) $\% \mathrm{SaO}_{2}$ and (C) heart rate were measured at baseline and then after administration of cumulative oxycodone doses study (Sacerdote et al., 1997), whereby administration of $10 \mathrm{mg} / \mathrm{kg}$ naltrexone 60 minutes prior to tissue collection and analysis showed elevated interleukin-2 production, suggesting elevated T cell activation (Liao et al., 2011). Chronic exposure in the current study versus acute exposure in the Sacerdote et al. (1997) study may explain these differences. Other studies have shown the use of naltrexone as an adjuvant to increase $\mathrm{IgG}_{1}$ and $\mathrm{IgG}_{2 \mathrm{a}}$ antibody levels for vaccines against various parasites in mice (Tappeh et al., 2013; Mohammadzadeh Hajipirloo et al., 2014; Khorshidvand et al., 2016; Azizi et al., 2018). The authors suggested that naltrexone may promote a type 1 helper $\mathrm{T}$ cell and cellular immune response by increasing local proinflammatory neuropeptides and may also block opioid receptors on innate immune cells to promote local inflammation. Interference at the B cell receptor could reduce $B$ cell activation and hapten-specific antibody production. Nevertheless, the immunomodulatory effect of XRNTX in the current study was minimal, and all observed oxycodone-specific IgG antibody titers were within the range previously described for OXY-KLH (Pravetoni et al., 2012a,b, 2013; Laudenbach et al., 2015; Raleigh et al., 2018).

Drug-induced motor activity has been previously used as a means of screening vaccination efficacy against opioids and other drugs of abuse (Carrera et al., 2001; Cornish et al., 2011; Li et al., 2011; Wee et al., 2012; Raleigh et al., 2013; Robinson et al., 2019). Fewer studies have characterized oxycodoneinduced motor activity (Leri and Burns, 2005; Niikura et al., 2013) or tested the preclinical efficacy of XR-NTX in preventing oxycodone-induced behaviors (Bartus et al., 2003; Dean et al., 2008). In the current study, vaccination with OXY-KLH alone had mixed effects on oxycodone-induced motor activity. At low oxycodone doses $(0.5 \mathrm{mg} / \mathrm{kg})$, OXY-KLH reduced oxycodone-induced motor activity if antibody titers were above $200 \times 10^{3}$ but not if titers were under $50 \times 10^{3}$. At oxycodone doses at or above $1.0 \mathrm{mg} / \mathrm{kg}$, vaccine alone did not alter motor activity. In contrast, a previous publication demonstrated that OXY-KLH in alum reduced oxycodone-induced motor activity after a much larger oxycodone dose of $5 \mathrm{mg} / \mathrm{kg}$ in mice (Robinson et al., 2019). However, rats and mice demonstrate differences in metabolism of oxycodone, which may in part explain why oxycodone doses differed so much between studies (Ishida et al., 1982). In fact, doses of oxycodone that exceeded $2.0 \mathrm{mg} / \mathrm{kg}$ began showing reduced motor activity compared with lower doses, suggesting that these doses are not appropriate for testing vaccine and XR-NTX effects.

Combination of OXY-KLH and XR-NTX using high doses of XR-NTX (50 mg/kg) had no effect over XR-NTX alone because of the high XR-NTX dose. However, human doses are around $5.4 \mathrm{mg} / \mathrm{kg}$ (Bisaga et al., 2018). Thus, high XR-NTX doses may not reflect real-world application of a combination therapy. In the current study, XR-NTX doses that were half of typical human doses $(2.25-2.5 \mathrm{mg} / \mathrm{kg})$ were combined with OXY-KLH and demonstrated reduced motor activity compared with controls. Furthermore, combination of XR-NTX and OXY$\mathrm{KLH}$ was more effective than vaccine alone in reducing

every 17 minutes subcutaneously. Data are expressed as mean \pm S.E.M. Two-way ANOVA with Bonferroni post-test was performed to compare groups to controls, and a separate two-way ANOVA with Bonferroni posttest was performed to compare each group to its baseline. $* P<0.05 ; * * P<$ $0.01 ; * * * P<0.001$ different from saline control; ${ }^{++} P<0.01$ different from OXY-KLH; ${ }^{*} P<0.05$ different from baseline. 
oxycodone-induced respiratory depression and bradycardia. Only one study has previously measured the effect of XR-NTX (at a dose of $50 \mathrm{mg} / \mathrm{kg}$ ) on opioid-induced respiratory depressive effects (respiratory rate) and found that pretreatment with XR-NTX prevented fentanylinduced respiratory depression (Dean et al., 2008). Combined, these data support the use of a combination therapy of OXY-KLH and XR-NTX.

The clinical efficacy of vaccines against prescription opioids, and against opioids in general, may be limited by highly variable and low serum antibody concentrations achieved in immunized subjects or by the occurrence of opioid users switching or transitioning between prescription opioids and other opioids, such as heroin or fentanyl. These limitations can be overcome by combining vaccination with medications targeting opioid receptors. Opioid antagonists may provide additional protection at the beginning of the vaccination regimen prior to development of clinically effective serum antibody titers and may enhance efficacy of vaccination in people who are relatively poor vaccine responders by providing additional blockage against the effects of prescription opioids. Additionally, if vaccination does not interfere with the efficacy of XR-NTX, patients wishing to change their type of treatment may do so without fear of losing efficacy during the transition.

\section{Acknowledgments}

The authors thank the Socrates program and the Department of Pharmaceutical Sciences at Universita' degli Studi di Milano for providing funding for exchange graduate student Claudia Accetturo. The authors thank Dr. Mark LeSage for insightful discussions on the study.

\section{Authorship Contributions}

Participated in research design: Accetturo, Pravetoni.

Conducted experiments: Raleigh, Accetturo.

Contributed new reagents or analytical tools: Pravetoni.

Performed data analysis: Raleigh, Accetturo, Pravetoni.

Wrote or contributed to the writing of the manuscript: Raleigh, Accetturo, Pravetoni.

\section{References}

Anton B and Leff P (2006) A novel bivalent morphine/heroin vaccine that prevents relapse to heroin addiction in rodents. Vaccine 24:3232-3240.

Azizi H, Mirzaeei H, Nasiri AA, Bazi A, Mirzapour A, Khatami M, Nahavandi KH, Azimi A, and Yaghoobi H (2018) Naltrexone; as an efficient adjuvant in induction of Th1 immunity and protection against Fasciola hepatica infection. Exp Parasitol 189:66-71.

Bartus RT, Emerich DF, Hotz J, Blaustein M, Dean RL, Perdomo B, and Basile AS (2003) Vivitrex, an injectable, extended-release formulation of naltrexone, provides pharmacokinetic and pharmacodynamic evidence of efficacy for 1 month in rats. Neuropsychopharmacology 28:1973-1982.

Bigelow GE, Preston KL, Schmittner J, Dong Q, and Gastfriend DR (2012) Opioid challenge evaluation of blockade by extended-release naltrexone in opioid-abusing adults: dose-effects and time-course. Drug Alcohol Depend 123:57-65.

Bisaga A, Mannelli P, Sullivan MA, Vosburg SK, Compton P, Woody GE, and Kosten TR (2018) Antagonists in the medical management of opioid use disorders: historical and existing treatment strategies. Am J Addict 27:177-187.

Bonese KF, Wainer BH, Fitch FW, Rothberg RM, and Schuster CR (1974) Changes in heroin self-administration by a rhesus monkey after morphine immunisation. Nature 252:708-710.

Boström E, Simonsson US, and Hammarlund-Udenaes M (2005) Oxycodone pharmacokinetics and pharmacodynamics in the rat in the presence of the P-glycoprotein inhibitor PSC833. J Pharm Sci 94:1060-1066.

Boström E, Simonsson US, and Hammarlund-Udenaes M (2006) In vivo blood-brain barrier transport of oxycodone in the rat: indications for active influx and implications for pharmacokinetics/pharmacodynamics. Drug Metab Dispos 34: $1624-1631$

Carrera MR, Ashley JA, Wirsching P, Koob GF, and Janda KD (2001) A secondgeneration vaccine protects against the psychoactive effects of cocaine. Proc Natl Acad Sci USA 98:1988-1992.

Cornish KE, Harris AC, LeSage MG, Keyler DE, Burroughs D, Earley C, and Pentel PR (2011) Combined active and passive immunization against nicotine: minimizing monoclonal antibody requirements using a target antibody concentration strategy. Int Immunopharmacol 11:1809-1815.

Cornuz J, Zwahlen S, Jungi WF, Osterwalder J, Klingler K, van Melle G, Bangala Y, Guessous I, Müller P, Willers J, et al. (2008) A vaccine against nicotine for smoking cessation: a randomized controlled trial. PLoS One 3:e2547.

Coviello DM, Cornish JW, Lynch KG, Boney TY, Clark CA, Lee JD, Friedmann PD, Nunes EV, Kinlock TW, Gordon MS, et al. (2012) A multisite pilot study of extended-release injectable naltrexone treatment for previously opioid-dependent parolees and probationers. Subst Abus 33:48-59.

Dean RL, Todtenkopf MS, Deaver DR, Arastu MF, Dong N, Reitano K, O'Driscoll K, Kriksciukaite K, and Gastfriend DR (2008) Overriding the blockade of antinociceptive actions of opioids in rats treated with extended-release naltrexone. Pharmacol Biochem Behav 89:515-522.

DeFulio A, Everly JJ, Leoutsakos JM, Umbricht A, Fingerhood M, Bigelow GE, and Silverman K (2012) Employment-based reinforcement of adherence to an FDA approved extended release formulation of naltrexone in opioid-dependent adults: a randomized controlled trial. Drug Alcohol Depend 120:48-54.

Dodrill CL, Helmer DA, and Kosten TR (2011) Prescription pain medication dependence. Am J Psychiatry 168:466-471.

Hatsukami DK, Jorenby DE, Gonzales D, Rigotti NA, Glover ED, Oncken CA, Tashkin DP, Reus VI, Akhavain RC, Fahim RE, et al. (2011) Immunogenicity and smoking-cessation outcomes for a novel nicotine immunotherapeutic. Clin Pharmacol Ther 89:392-399.

Ishida T, Oguri K, and Yoshimura H (1982) Determination of oxycodone metabolites in urines and feces of several mammalian species. $J$ Pharmacobiodyn 5:521-525.

Johanson CE, Arfken CL, di Menza S, and Schuster CR (2012) Diversion and abuse of buprenorphine: findings from national surveys of treatment patients and physicians. Drug Alcohol Depend 120:190-195.

Jones CM, Einstein EB, and Compton WM (2018) Changes in synthetic opioid involvement in drug overdose deaths in the United States, 2010-2016. JAMA 319: $1819-1821$

Kelty E and Hulse G (2012) Examination of mortality rates in a retrospective cohort of patients treated with oral or implant naltrexone for problematic opiate use. Addiction 107:1817-1824.

Khorshidvand Z, Shahabi S, Mohamadzade H, Daryani A, and Hazrati Tappeh K (2016) Mixture of Alum--Naloxone and Alum--Naltrexone as a novel adjuvant elicits immune responses for Toxoplasma gondii lysate antigen in BALB /c mice. Exp Parasitol 162:28-34.

Kjome KL and Moeller FG (2011) Long-acting injectable naltrexone for the management of patients with opioid dependence. Subst Abuse 5:1-9.

Krupitsky E, Nunes EV, Ling W, Gastfriend DR, Memisoglu A, and Silverman BL (2013) Injectable extended-release naltrexone (XR-NTX) for opioid dependence: long-term safety and effectiveness. Addiction 108:1628-1637.

Krupitsky E, Nunes EV, Ling W, Illeperuma A, Gastfriend DR, and Silverman BL (2011) Injectable extended-release naltrexone for opioid dependence: a doubleblind, placebo-controlled, multicentre randomised trial. Lancet 377:1506-1513.

Laudenbach M, Baruffaldi F, Vervacke JS, Distefano MD, Titcombe PJ, Mueller DL, Tubo NJ, Griffith TS, and Pravetoni M (2015) The frequency of naive and earlyactivated hapten-specific B cell subsets dictates the efficacy of a therapeutic vaccine against prescription opioid abuse. J Immunol 194:5926-5936.

Leri $\mathrm{F}$ and Burns LH (2005) Ultra-low-dose naltrexone reduces the rewarding potency of oxycodone and relapse vulnerability in rats. Pharmacol Biochem Behav 82: 252-262.

Li QQ, Luo YX, Sun CY, Xue YX, Zhu WL, Shi HS, Zhai HF, Shi J, and Lu L (2011) A morphine/heroin vaccine with new hapten design attenuates behavioral effects in rats. $J$ Neurochem 119:1271-1281.

Liao W, Lin JX, and Leonard WJ (2011) IL-2 family cytokines: new insights into the complex roles of IL-2 as a broad regulator of T helper cell differentiation. Curr Opin Immunol 23:598-604.

Martell BA, Orson FM, Poling J, Mitchell E, Rossen RD, Gardner T, and Kosten TR (2009) Cocaine vaccine for the treatment of cocaine dependence in methadonemaintained patients: a randomized, double-blind, placebo-controlled efficacy trial. Arch Gen Psychiatry 66:1116-1123.

Metcalf MD, Rosicky AD, Hassan HE, Eddington ND, Coop A, Cunningham CW, and Mercer SL (2014) Opioids and efflux transporters. Part 4: influence of $\mathrm{N}$-substitution on P-glycoprotein substrate activity of noroxymorphone analogues. Bioorg Med Chem Lett 24:3592-3595.

Miotto K, McCann MJ, Rawson RA, Frosch D, and Ling W (1997) Overdose, suicide attempts and death among a cohort of naltrexone-treated opioid addicts. Drug Alcohol Depend 45:131-134.

Mohammadzadeh Hajipirloo H, Bozorgomd A, Shahabi S, Hazrati Tappeh K and Karamati SA (2014) Evaluation of alum-naltrexone adjuvant activity, on efficacy of anti-leishmania immunization with autoclaved leishmania major (MRHO/ IR/75/ER) antigens in BALB/C mice. Iran J Parasitol 9:311-318.

Nakazawa Y, Okura T, Shimomura K, Terasaki T, and Deguchi Y (2010) Drug-drug interaction between oxycodone and adjuvant analgesics in blood-brain barrier transport and antinociceptive effect. J Pharm Sci 99:467-474.

Nguyen JD, Hwang CS, Grant Y, Janda KD, and Taffe MA (2018) Prophylactic vaccination protects against the development of oxycodone self-administration. Neuropharmacology 138:292-303.

Niikura K, Ho A, Kreek MJ, and Zhang Y (2013) Oxycodone-induced conditioned place preference and sensitization of locomotor activity in adolescent and adult mice. Pharmacol Biochem Behav 110:112-116.

Nunes EV, Krupitsky E, Ling W, Zummo J, Memisoglu A, Silverman BL, and Gastfriend DR (2015) Treating opioid dependence with injectable extendedrelease naltrexone (XR-NTX): who will respond? J Addict Med 9:238-243.

Okura T, Hattori A, Takano Y, Sato T, Hammarlund-Udenaes M, Terasaki T, and Deguchi Y (2008) Involvement of the pyrilamine transporter, a putative organic cation transporter, in blood-brain barrier transport of oxycodone. Drug Metab Dispos 36:2005-2013. 
Pravetoni M, Le Naour M, Harmon TM, Tucker AM, Portoghese PS, and Pentel PR (2012a) An oxycodone conjugate vaccine elicits drug-specific antibodies that reduce oxycodone distribution to brain and hot-plate analgesia. J Pharmacol Exp Ther 341:225-232.

Pravetoni M, Le Naour M, Tucker AM, Harmon TM, Hawley TM, Portoghese PS, and Pentel PR (2013) Reduced antinociception of opioids in rats and mice by vaccination with immunogens containing oxycodone and hydrocodone haptens. J Med Chem 56:915-923.

Pravetoni M, Pentel PR, Potter DN, Chartoff EH, Tally L, and LeSage MG (2014a) Effects of an oxycodone conjugate vaccine on oxycodone self-administration and oxycodone-induced brain gene expression in rats. PLoS One 9:e101807.

Pravetoni M, Raleigh MD, Le Naour M, Tucker AM, Harmon TM, Jones JM, Birnbaum AK, Portoghese PS, and Pentel PR (2012b) Co-administration of morphine and oxycodone vaccines reduces the distribution of 6 -monoacetylmorphine and oxycodone to brain in rats. Vaccine 30:4617-4624.

Pravetoni M, Vervacke JS, Distefano MD, Tucker AM, Laudenbach M, and Pentel PR (2014b) Effect of currently approved carriers and adjuvants on the pre-clinical efficacy of a conjugate vaccine against oxycodone in mice and rats. PLoS One $\mathbf{9}$ e96547.

Pravetoni M and Wickman K (2008) Behavioral characterization of mice lacking GIRK/Kir3 channel subunits. Genes Brain Behav 7:523-531.

Raleigh MD, Laudenbach M, Baruffaldi F, Peterson SJ, Roslawski MJ, Birnbaum AK, Carroll FI, Runyon SP, Winston S, Pentel PR, et al. (2018) Opioid dose- and route-dependent efficacy of oxycodone and heroin vaccines in rats. $J$ Pharmacol Exp Ther 365:346-353.

Raleigh MD, Peterson SJ, Laudenbach M, Baruffaldi F, Carroll FI, Comer SD, Navarro HA, Langston TL, Runyon SP, Winston S, et al. (2017) Safety and efficacy of an oxycodone vaccine: addressing some of the unique considerations posed by opioid abuse. PLoS One 12:e0184876.

Raleigh MD, Pravetoni M, Harris AC, Birnbaum AK, and Pentel PR (2013) Selective effects of a morphine conjugate vaccine on heroin and metabolite distribution and heroin-induced behaviors in rats. $J$ Pharmacol Exp Ther 344:397-406.
Robinson C, Baehr C, Schmiel SE, Accetturo C, Mueller DL, and Pravetoni M (2019) Alum adjuvant is more effective than MF59 at prompting early germinal center formation in response to peptide-protein conjugates and enhancing efficacy of a vaccine against opioid use disorders. Hum Vaccin Immunother 15: 909-917.

Sacerdote P, Manfredi B, Mantegazza P, and Panerai AE (1997) Antinociceptive and immunosuppressive effects of opiate drugs: a structure-related activity study. $\mathrm{Br}$ $J$ Pharmacol 121:834-840.

Sadiq MW, Borgs A, Okura T, Shimomura K, Kato S, Deguchi Y, Jansson B, Björkman S, Terasaki T, and Hammarlund-Udenaes M (2011) Diphenhydramine active uptake at the blood-brain barrier and its interaction with oxycodone in vitro and in vivo. J Pharm Sci 100:3912-3923.

Stowe GN, Vendruscolo LF, Edwards S, Schlosburg JE, Misra KK, Schulteis G, Mayorov AV, Zakhari JS, Koob GF, and Janda KD (2011) A vaccine strategy that induces protective immunity against heroin. J Med Chem 54:5195-5204.

Tappeh KH, Khorshidvand Z, Shahabi S, and Mohammadzadeh H (2013) A novel adjuvant, mixture of Alum and naltrexone, elicits humoral immune responses for excreted/secreted antigens of Toxoplasma gondii tachyzoites vaccine in Balb/c murine model. Turkiye Parazitol Derg 37:92-96.

Volkow ND and Collins FS (2017) The role of science in addressing the opioid crisis. N Engl J Med 377:391-394.

Wee S, Hicks MJ, De BP, Rosenberg JB, Moreno AY, Kaminsky SM, Janda KD, Crystal RG, and Koob GF (2012) Novel cocaine vaccine linked to a disrupted adenovirus gene transfer vector blocks cocaine psychostimulant and reinforcing effects. Neuropsychopharmacology 37:1083-1091.

WHO (2018) Information sheet on opioid overdose.

Address correspondence to: Marco Pravetoni, University of Minnesota, Department of Pharmacology, 3-108 Nils Hasselmo Hall, 312 Church St. SE, Minneapolis, MN 55455. E-mail: prave001@umn.edu 